\title{
Are specialists really safer than generalists for classical biocontrol?
}

\author{
Joseph Michael Taylor $\mathbb{D} \cdot$ William Emerson Snyder $\mathbb{D}$
}

Received: 28 February 2020/Accepted: 27 July 2020/Published online: 6 August 2020

(C) The Author(s) 2020

\begin{abstract}
Generalists rarely are considered for classical biocontrol because their broad feeding habits are expected to make non-target impacts inevitable. This assumes an increase in overall ecological risk with increasing number of feeding connections. With the goal of inspiring fresh consideration of the safety of exotic biocontrol agents for classical biocontrol, we present a selective review of the impacts of nine particularly-well-studied exotic natural enemies ranging from relative specialists to generalists. Surprisingly, non-target effects could be particularly strong for relative specialists that attacked just a few natives, but were often widespread but weak for the broadest generalists. This appeared to reflect relatively strong apparent competition and density-dependence for the narrow feeders, versus broadly diffuse net effects for the broader feeders. Overall, we suggest a sole focus on specialists in classical biocontrol might be an unreliable means to reduce ecological risk. Additional research is needed to fully compare the net direct and indirect effects of generalists and specialists across food webs, following classical biocontrol releases.
\end{abstract}

Handling Editor: Debora Pires Paula.

J. M. Taylor $(\bowtie) \cdot$ W. E. Snyder

Department of Entomology, University of Georgia,

Athens, GA 30621, USA

e-mail: joseph.taylor1@uga.edu
Keywords Non-target effects · Risk assessment . Predator $\cdot$ Parasitoid $\cdot$ Non-native $\cdot$ Release

\section{Introduction}

Biological control was initiated, in its earliest days, as a strategy to manage invasive pests that had escaped their natural enemies when moving to new continents (Hajek and Eilenberg 2018). When successful, this approach has the potential to dramatically and sustainably reduce pest numbers and damage without the need for costly chemical or other pest controls (Hajek and Eilenberg 2018). However, broad-feeding generalists initially had a rocky history as introduced biological control agents. Problems began with the disastrous early introductions of generalist vertebrates such as the mongoose (Herpestes javanicus) in Hawaii and the cane toad (Rhinella marina) in Australia (Shine 2010), which caused devastating and widereaching ecological harm with little evidence that pest control was enhanced.

Things further worsened for generalists when evidence began to emerge that seemingly safer, smaller invertebrate generalists might also be having undesirable non-target effects. Examples include the decline of native Hawaiian puncture vine (Tribulus cistoides) by the herbivorous weevil Microlarinus spp. that was intended to control the vine's invasive 
congener Tribulus terrestris (Andres and Goeden 1971), and the extinction of several native Hawaiian land snails by the introduced predatory snail Euglandina rosea that was originally intended to control various pest gastropods (Civeyrel and Simberloff, 1996). In each of these cases, the generalists fed not only on the control targets but also on other naïve prey, which as part of depauperate island faunas had no coevolutionary history with similar natural enemies. In the wake of these disasters the safety of all biological control efforts, not just those involving broad generalists, was called into question amid numerous calls for stricter host-specificity testing (e.g., De Clercq et al. 2011; Howarth 1983; Stiling and Simberloff 2000). The time and cost associated with this testing likely contributed to an overall decrease in classical biocontrol releases in North America and Europe, which have been responsible for a plurality of introductions (Fig. 1; Cock et al. 2016; Greathead and Greathead 1992; Babendreier et al 2006).

Arguably a central, although not often examined, tenet of linking ecological safety to specialization is the assumption that risk is greater with an increasing number of feeding links. With the goal of initiating discussion with the biocontrol community, here we pose the possibility that there could be reason to doubt this assumption (Fig. 2). Of course, an absolute specialist that feeds only on the control target, while being incapable of attacking any other prey/host species, cannot directly endanger any other species. But this does not mean that indirect effects of a strict specialist on natives will be weak (e.g., Callaway et al. 1999; Louda and Arnett 1999; Pearson and Callaway 2003). In addition, past the point of pure, singlespecies specialization, there is reason to think that variation in the magnitude of effects on particular native non-targets might not remain constant with increasing generality of feeding (Fig. 2). Indeed, evolutionary responses through time can lead to changes in the degree of host specificity following introduction (e.g., Tomasetto et al. 2017).

One possible complication is the common observation that natural enemies that simultaneously attack just a small handful of prey/host species are wellknown to engage in "apparent competition" (sensu Holt 1977). Apparent competition occurs when predators supported by feeding on one prey species reach higher densities than they otherwise might, with these elevated predator densities leading to heightened predation on a second prey/host species (Holt 1977).

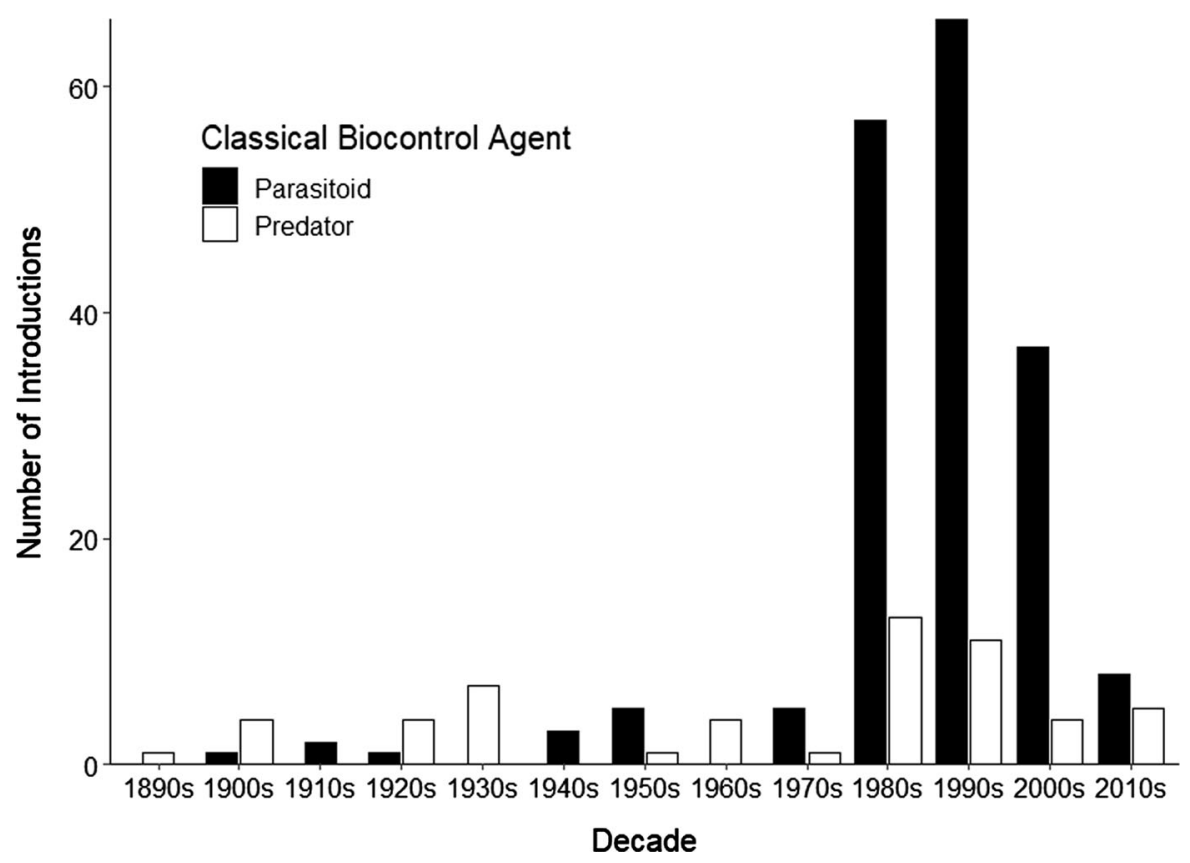

Fig. 1 Number of exotic predator and parasitoid biocontrol agents released in North American and US territories and Europe, each decade from the $1890 \mathrm{~s}$ to 2010s. For species

introduced several times, only the initial release is displayed. Date from van Driesche et al. (2018) and Gerber and Schaffner (2016) 


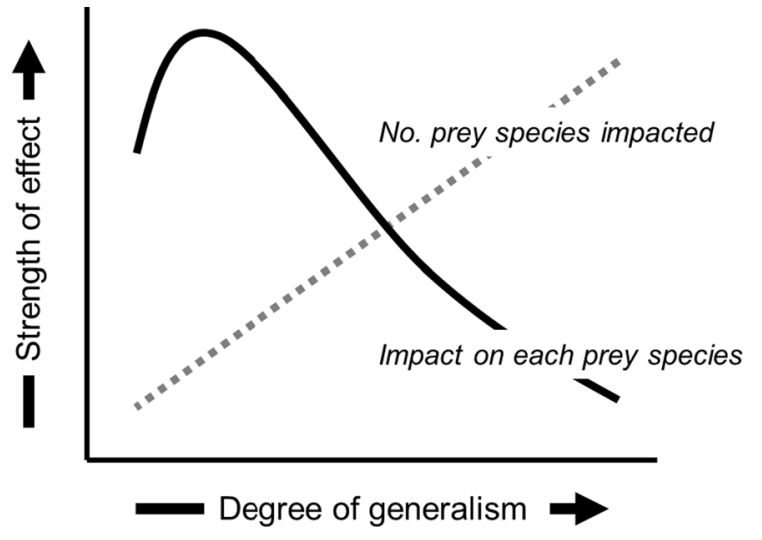

Fig. 2 A simple graphical model of one possible relationship between degree of specialization by a natural enemy released for classical biological control and the magnitude of resulting effect, for the number of prey species impacted (dashed line) and the impact on each prey species (solid line)

This means that occasional "slip ups" in fully delineating a relatively specialized natural enemy's modest degree of polyphagy might yield relatively few, but particularly strong, non-target impacts (Fig. 2, 3). In contrast, the broadest generalists, by definition, feed on many different prey species and often across trophic levels (Polis et al. 1989). This means that non-target impacts will be widespread, sometimes remarkably so (e.g., Hurd et al. 2015; Hurd and Eisenberg 1990; Fig. 4). Yet, because the broad generalist enemy is not particularly dependent on, or able to dramatically benefit from, any single prey/host

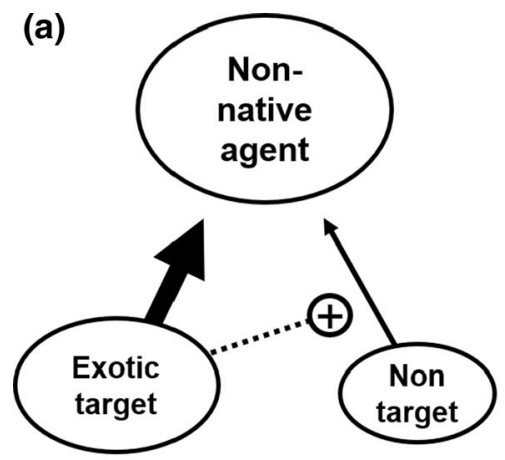

Fig. 3 a A relatively specialized agent that strongly impacts the control target, with relatively little feeding on a non-target, might nonetheless exert considerable harm through "apparent competition" when agents reach large numbers while feeding on the target and spillover to attack the native. b When a control target provides habitat or supplemental food resources for a native species, the agent can indirectly harm the native by species, the abundant non-target effects might each individually be relatively weak (Fig. 2). Indeed, this type of broadly diffuse feeding relationships can dampen predator-prey oscillations to make exceptionally high densities of a particular pest species less likely (McCann et al. 1998).

Here, we provide an initial exploration of the relationship between a natural enemy species' degree of feeding specialization/generalization, and the number and strength of non-target impacts. We take advantage of detailed ecological work for nine particularly well-studied introduced insects. In our selective review, because very broad generalists are usually excluded from classical biocontrol programs, we had to rely on several case studies where the natural enemy was accidentally rather than intentionally released. So, our goal is not to examine or critique previous biocontrol releases. Rather, we intend to initiate a broader discussion of the relationship between specialization and ecological safety using the most complete case studies available in the literature. These ranged from the relative specialist weevil Rhinocyllus conicus (Coleoptera: Curclionidae), leaf beetle Diorhabda elongata (Coleoptera: Chrysomelidae), and parasitoids Cotesia rubecula and Cotesia glomeratea (Hymonoptera: Eulophidae), to the intermediate polyphagous beetles Coccinella septempunctata and Harmonia axyridis (Coleoptera: Coccinellidae) and the tachinid fly Compsiluara concinnata (Diptera: Tachinidae), then to the broadly polyphagous

(b)

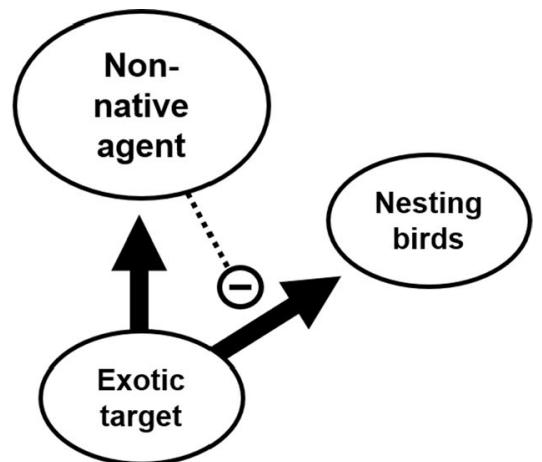

removing these resources. Solid lines indicate direct interactions and point from resource to consumer. Dashed lines indicate indirect effects, with those ending in "+" indicating an indirect effect that enhances the interaction and those ending in a "-" indicating an indirect effect that weakens the interaction. Thicker lines indicate relatively stronger interactions 


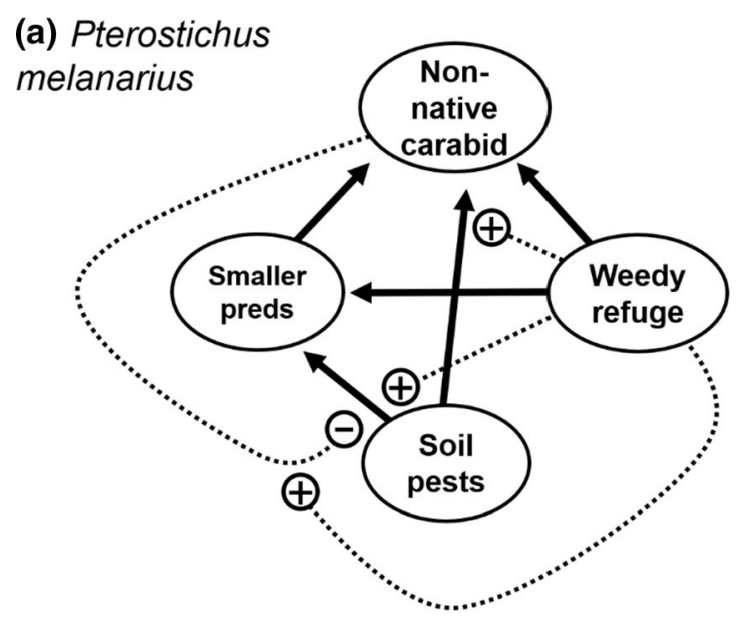

Fig. 4 In North America, interactions between two non-native, broadly generalist predators and their communities. a The ground beetle Pterostichus melanarius feeds both on pests, strengthening biological control, and on smaller generalist predators, weakening biological control. The net impact of these counterbalancing positive and negative effects is further mediated by weedy refuge plantings that can benefit both the smaller native predators and the intraguild predator $P$. melanarius. b Likewise, the praying mantis Tenodera sinensis feeds directly on some herbivores while also attacking wolf spiders and other smaller generalist predators. Wolf spiders will

generalist praying mantid Tenodera sinensis (Mantodea: Mantidae) and ground beetle Pterostichus melanarius (Coleoptera: Carabidae). We use these case studies to examine how host-specificity, or lack thereof, impacted the severity of their non-target effects through both direct and indirect channels.

\section{Case studies}

Too hot? Relatively narrow specialists

\section{The weevil Rhinocyllus conicus}

Rhinocyllus conicus was introduced to North America in the late 1960s to early 1990s to control Carduus nutans and other invasive European thistles (Kok 2001; Kok and Surles 1975; Turner et al. 1987). Like many weed biocontrol agents, $R$. conicus underwent host-specificity testing before release, which included documenting an apparent preference for attacking the target weed $C$. nutans and low usage and larval survival on non-target thistles (Zwölfer and Harris 1984). In addition to this perceived narrow host range,

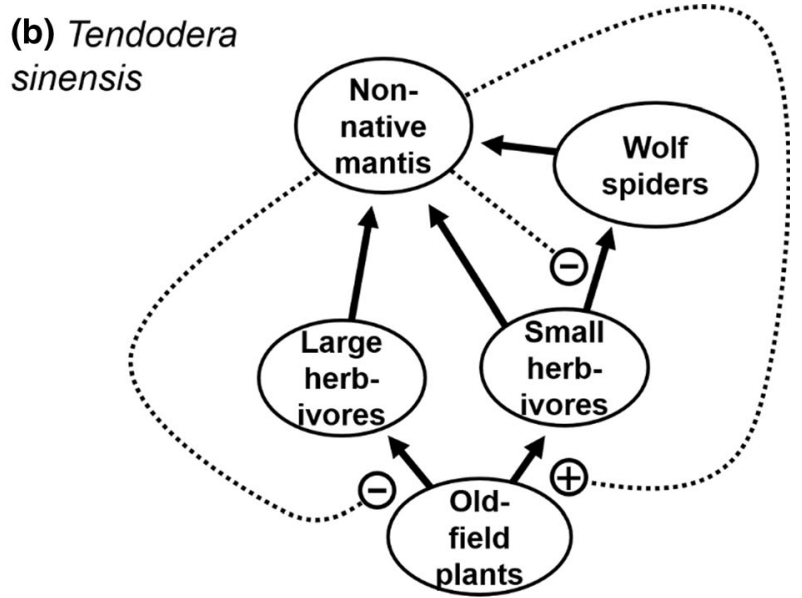

leave areas where mantids are present, further weakening the spiders' impacts on herbivores. This leads the mantid to exert a complex mix of indirect benefit to plants through direct suppression of herbivores that is largely counterbalanced by indirect harm to plants mediated by intraguild predation. Solid lines indicate direct interactions and point from resource to consumer. Dashed lines indicate indirect effects, with those ending in "+" indicating an indirect effect that enhances the interaction and those ending in "-" indicating an indirect effect that weakens the interaction

it was also hypothesized that $R$. conicus would be outcompeted by native seed predators on any native thistles because the weevil is relatively uncompetitive with guildmates in its home range (Zwölfer 1979). These initial studies laid the groundwork for what seemed like the perfect scenario of high target impacts and little native spillover, to the far left of Fig. 2. However, while reducing seed count of $C$. nutans by over $90 \%, R$. conicus also attacked the rare Platte thistle, Cirsium canescens (Louda et al. 2003; Wiggins et al. 2010). This non-target utilization occurred despite the preference $R$. conicus still exhibited for its control target, C. nutans (Arnett and Louda 2002; Gassmann and Louda 2001). Apparently, abundant $R$. conicus emerging from the biocontrol target "spill over" to also attack the less-preferred, at-risk native plant (Blitzer et al. 2012), that is, the classic apparent competition scenario (Fig. 3a). Overall, this forms an example of the particular risk that relative specialists can pose to non-targets when they spill over from large populations on the control target, shown as the peak on the left side of our specialism-generalism risk model (Fig. 2). 
The parasitoid wasps Cotesia rubecula and Cotesia glomerata

Comparing the closely related parasitoid wasps $C$. rubecula and $C$. glomerata further elucidates the line that relatively specialized control agents can straddle, from relatively pure focus on a target pest to apparent competition, spillover, and harm to sensitive natives. While not part of formal biocontrol programs, the Cotesia spp. either entered North America accidentally or as part of amateur control efforts (Clausen 1978; Scudder 1889). Of the two, C. rubecula is considered to be a nearly complete specialist on the crucifer pest Pieris rapae. In contrast, its congener $C$. glomerata attacks both $P$. rapae and related, native non-target Pieris spp. (Brodeur et al. 1996; Krombein et al. 1979). In turn, C. glomerata's relative polyphagy has been linked to the shrinking ranges of the sensitive native Pieris napi oleracea (van Driesche et al. 2004). This is because, in areas where the parasitoid occurs alongside both $P$. rapae and $P$. $n$. oleracea, $C$. glomerata parasitoids emerging from the relatively abundant $P$. rapae spill over to attack $P$. n. oleracea, that is, yet another example of apparent competition that is harmful to a native non-target (Fig. 3a; Benson et al.2003a, 2003b). In summary, the two Cotesia species appear on opposite sides of the inflexion point between nearly-pure specialization on a pest without substantial spillover to non-targets in the case of $C$. rubecula, versus the slight increase in generalism leading to spillover and harmful apparent competition for C. glomerata (Fig. 2, 3a; Cameron and Walker 2002; van Driesche et al. 2003).

\section{The herbivorous beetle Diorhabda elongata}

The herbivorous leaf beetle $D$. elongata was introduced into the western US to control non-native saltcedars (Tamarix spp.), which invade and come to dominate riparian areas. As a relatively recent biocontrol introduction, host specificity for the beetle was a high priority, as was its destructive potential against the control target (DeLoach et al. 2003). Host specificity tests evaluated D. elongata preference and performance on non-target shrubs. Though usage of Frankensia, a close relative of Tamarix, was as high as $15 \%$ in some studies, field tests yielded minimal evidence of risk for defoliation in a more "natural" setting for native Frankensia or Tamarix aphylla plants (Dudley and Kazmer 2005; Herr et al. 2009; Lewis et al. 2003). With little apparent risk, D. elongata was released in the early 2000s. Follow-up studies have found little evidence that $D$. elongata has adapted to utilize natives more than initial host testing had predicted (Pratt et al. 2019). In terms of our theoretical model, then, D. elongata would appear to be a prime example of a nearly-pure specialist, with near-total focus on the control target that is thought to be associated with no measurable non-target effects (far left side of Fig. 2).

However, there may be reason for caution. Most significantly, the rapid removal of Tamarix from its invaded range may harm endangered bird species that rely on these trees for nesting sites (Fig. 3b; Bean and Dudley, 2018; Paxton et al., 2011; Sogge et al., 2008). This is a classic example of a strong indirect effect on native communities that can lead to harmful non-target effects even when direct harm to non-targets is relatively weak. It must be noted that the effectiveness of this classical biological control effort relative to chemical or other weed control methods also, perhaps somewhat ironically, underlies the strength of its unintended indirect effect on the birds. Furthermore, several ecotypes of D. elongata have been released, and hybridization between these "strains" could lower host-specificity in the future (Bitume et al. 2017). There also is some initial evidence that the beetles' host fidelity may be reduced after establishment when compared to a laboratory reared cohort (Thomas et al. 2010). This sets up the possibility that apparent competition could emerge, if large populations of beetles on invasive Tamarix begin spilling over to increasingly attack its native relatives. That is, the situation could move towards the "increased risk hump" on the left side of our conceptual model, reflecting increasingly-strong apparent competition (Fig. 2).

Too cold? Broad generalists

\section{The praying mantid Tenodera sinensis}

The praying mantis $T$. sinensis, native to Asia, does not appear to have been intentionally introduced into North America. Rather, it may have arrived in egg sacs attached to nursery stock (Hurd et al. 2015). Regardless, this mantis has been the subject of extensive study, including a series of manipulative field studies 
in the old-field early successional plant communities where they occur, that provide detailed insight into ecological effects in the invaded range (e.g., Hurd and Eisenberg1990; Hurd et al. 2015). This has revealed that, while the mantid appears to exert a bewildering number and diversity of direct and indirect effects on other community members, no single link appears to be particularly strong. For example, comparison of large field plots with versus without $T$. sinensis populations revealed that these mantids weakly, directly suppressed numbers of larger herbivorous insects (Hurd and Eisenberg 1990). However, these predators also exerted complex effects on smaller herbivores through a balance between direct predation and release from predation by wolf spiders and other meso-predators (Hurd and Eisenberg 1990; Moran and Hurd 1998; Hurd et al. 2015). The mantids appear to drive wolf spiders from areas they inhabit as the spiders emigrate to avoid intraguild predation (Moran et al. 1996). Altogether, these varying effects on different predaceous and herbivorous prey species, through both direct and indirect channels and resulting both from actual predation and $T$. sinensis-induced changes in behavior, dampens any resulting trophic cascade impacting plant biomass (Hurd and Eisenberg 1990; Moran and Hurd 1998). So, from the standpoint of non-target effects, the news is generally good because while $T$. sinensis is impacting many different native species, these numerous links appear to be generally weak (Fig. 4a). From the standpoint of herbivore suppression, however, the many weak links do not sum to yield a dramatic increase in plant biomass (Fig. 4a). Were this a biocontrol system, then, $T$. sinensis is not substantially harming native nontargets but it also is not substantially strengthening natural control of herbivores to the benefit of plant yield (i.e., this case study equates to the far right of Fig. 2).

\section{The ground beetle Pterostichus melanarius}

The ground beetle Pterostichus melanarius is another broad generalist, native to Europe but accidentally introduced to North America in ship ballast, whose ecological impact bears many similarities to that of $T$. sinensis (Snyder and Evans 2006). In both the native and introduced range, $P$. melanarius appears quite tolerant of human disturbance and often is abundant in agricultural fields (Busch 2016). The beetles are remarkably polyphagous, feeding on a great diversity of herbivorous, predacious, and detritivorous arthropods and other prey species (e.g., Hagley et al. 1982). As with $T$. sinensis, this in turn leads to a diversity of direct and indirect effects that impact pest suppression. For example, in the northwestern US, $P$. melanarius feeds on eggs and larvae of Delia spp. flies that otherwise can heavily damage the roots of crucifer crops (Prasad and Snyder 2006). However, P. melanarius also triggers other ground and rove beetle species to forage less often, apparently as the smaller beetles seek to avoid intraguild predation, such that $P$. melanarius's direct feeding does not benefit the control of fly pests (Prasad and Snyder 2006). In turn, attempts to augment biological control by ground beetles by providing them with weedy refuges in or near agricultural fields, yields a complex mix of benefits and harms. The refuges benefit both $P$. melanarius and the smaller native predaceous beetles, strengthening control of herbivorous root-pest insects by the smaller beetles alongside disrupted foraging of these smaller predators in the presence of $P$. melanarius (unpublished data). On the whole, then, all of these many weaker feeding connections yield no clear net contribution towards, or disruption of, pest insects by $P$. melanarius. Furthermore, P. melanarius appears only to be common in disturbed habitats, and has not been found to disrupt native carabid communities in forests (Niemelä and Spence 1991). Even in more urban settings, where $P$. melanarius is abundant, native populations of carabids do not seem to suffer as a result (Niemelä and Kotze 2009). It may be that $P$. melanarius is primarily exploiting habitats to which native carabids are ill-suited, leaving a natural refuge for the natives in less-disturbed areas.

Just right? Intermediate generalists

The lady beetles Harmonia axyridis and Coccinella septempunctata

Some readers might be surprised by the labeling of these two generalists as "just right" for classical biocontrol. After all, H. axyridis and C. septempunctata are arguably two of the most-maligned non-native generalist predators where they have been released or have invaded. This largely stems from perceived harm the two lady beetles have done to native coccinellids, which is alleged to result, at least in part, from 
intraguild predation of natives by the non-natives (e.g., Brown and Roy 2018; Sloggett 2017). It is clear that the arrival of one or both of these lady beetles to new habitats has at least roughly correlated with fewer native lady beetles found foraging in agricultural fields (e.g., Alyokhin and Sewell 2004). But recent years have seen growing skepticism that fewer natives in cropping fields reflects a true regional decline outside of these highly-managed systems (e.g., Riddick 2017; Sloggett 2017). Some particularly elegant work was reported by Evans (2004), who recorded the neardisappearance of native lady beetles from Utah, USA, alfalfa (Medicago sativa) fields following the arrival of $C$. septempunctata. This seemed consistent with intraguild predation of the natives by $C$. septempunctata leading to native declines, although numbers of pea aphids (Acyrthosiphon pisum) in alfalfa also decreased, apparently due to relatively effective predation by $C$. septempunctata, such that resource competition could be at play. And indeed, when pea aphid densities were experimentally restored to preinvasion levels, native lady beetles once again returned to alfalfa (Evans 2004). This suggests that native lady beetles exploited the dense aphid resources that agricultural fields provided when available, but when aphid densities dropped the natives simply remained within the natural habitats they presumably had inhabited before the arrival of agriculture (Evans 2004). So, there is evidence in this case that $C$. septempunctata is having the desired effect, driving down numbers of pest aphids in agricultural fields, while native lady beetles find refuge in more-natural habitats.

Something similar may be at work for $H$. axyridis. Arrival of this non-native predator has been associated with declines in several previously-common aphid species in agricultural habitats (e.g., Riddick 2017), consistent with $H$. axyridis strengthening aphid biological control. In the midwestern US, years with relatively high densities of $H$. axyridis correlate with relatively few collections of ladybird beetles from in or near agricultural fields (Bahlai et al. 2015; Diepenbrock et al. 2016). Yet, native lady beetles remain relatively common in more-natural habitats, consistent with aphid suppression in agricultural fields due to $H$. axyridis predation driving natives back into natural habitats they utilized before the broad introduction of agriculture (Bahlai et al. 2015; Diepenbrock et al. 2016). Likewise, in Europe, it appears that the rise of
H. axyridis in urban habitats, where pollution-stressed trees experience relatively large aphid outbreaks, may simply be returning native Adalia lady beetles to natural habitats they had previously occupied (Viglášová et al. 2017). Apparent declines in Adalia had previously been attributed to intraguild predation by H. axyridis (e.g., Brown and Roy 2018). So, while there is little doubt that intraguild predation of natives by $H$. axyridis is common under laboratory conditions and also occurs in the field (e.g., Brown et al. 2015; Ware et al. 2009), it seems that depletion of prey resources in human-managed habitats is the main mechanism through which the non-native beetles are displacing natives (Alyokhin and Sewell 2004; Kindlmann et al. 2011) (Fig. 5). Again, of course, it is just this sort of depression of pest aphids in agricultural fields that is the goal of biological control. Both the relative segregation of $H$. axyridis into trees rather than herbaceous crops (Honek et al. 2019; Masetti et al. 2018), and the gradual accumulation of parasitoids attacking $H$. axyridis in the introduced range (e.g., Ceryngier et al. 2018) may further diminish any risk that these beetles pose to natives. More generally, both $C$. septempunctata and $H$. axyridis may fall into the "just right" place on our risk curve (Fig. 2), being sufficiently generalist to take advantage of alternative prey when pest aphids are not abundant, but specific (and mobile) enough to be drawn to pest aphid outbreaks when the occur (e.g., Bannerman et al. 2018). As a caveat is important to note, however, that

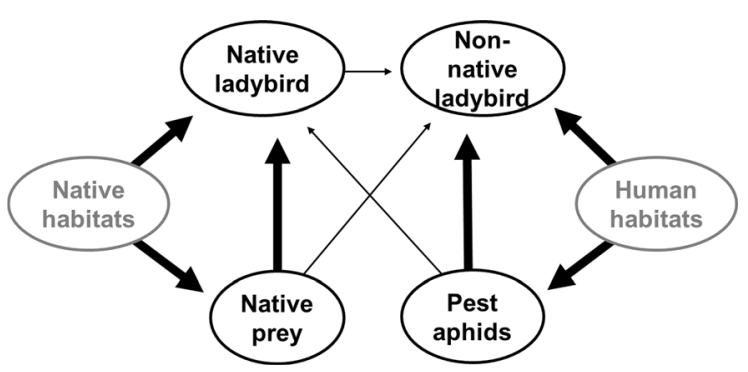

Fig. 5 The non-native ladybird beetles Coccinella septempunctata and Harmonia axyridis appear to concentrate their foraging in agricultural and other human-modified habitats, whereas native ladybirds may focus their foraging in lessdisturbed habitats. This can lead to improvement of biological control in cropping fields where the non-natives best tolerate disturbance and exploit pest outbreaks, while natives find refuge in the natural habitats where they presumably existed before conversion of land to agriculture. Solid lines indicate direct interactions and point from resource to consumer. Thicker lines indicate relatively stronger interactions 
while both $C$. septempunctata and $H$. axyridis are sometimes found in natural habitats alongside native lady beetles (e.g., Diepenbrock and Finke 2013; Grez et al. 2017) relatively little is known about their interactions there such that harm to the natives may be occurring that is not documented.

\section{The tachinid fly Compsilura concinnata}

In some respects, the tachinid fly $C$. concinnata is considered a classic example of why generalists should not be considered for classical biological control (Elkinton and Boettner 2012). In North America, the fly was first released in the early 1900s in an attempt to control two European invasives, the gypsy moth (Lymantria dispar) and the browntail moth (Euproctis chrysorrhoea), that were devastating hardwood forests (Elkinton and Boettner 2012). As these introductions were early in the twentieth century, formal host-specificity testing was not conducted but the fly was known to attack $>200$ species of lepidoptera and symphyta (Elkinton and Boettner 2012). Unfortunately, while the gypsy moths that were the primary target for control are univoltine and is only in the vulnerable larval stage at the beginning of the summer, $C$. concinnata is multivoltine and so must switch to attacking non-target hosts later in the growing season (Webber and Schaffner 1926; Weseloh 1982). Because native saturniid moth larvae are among the only vulnerable hosts later in the year, in turn this means that $C$. concinnata has spilled over to devastate these large, charismatic natives (Boettner et al. 2000; Kellogg et al. 2003). So, here again, this is a classic case of apparent competition, albeit with the control target and the most-impacted non-natives occurring separate in time (Elkinton and Boettner 2012). This case study presents a cautionary note, then, the moderate generalism will not always generate the "right" mix of strong effects on the target and relatively weak non-target harm. Further work will be needed to see whether the details of how non-target harm operates in this system-continuing relatively high densities of pests after the biocontrol introduction, relatively brief seasonal susceptibility of the control targets that is staggered with when the natives are susceptible-are broadly common in other systems.

\section{Discussion}

The need to document extreme specialization as the key criterion indicating safety of a natural enemy being considered for release, has greatly slowed progress in classical biological control (Cock et al. 2016; Follett et al. 2000; Messing and Wright 2006). After all, host-range testing is expensive, time consuming, and difficult to conduct under quarantine conditions (Messing 2009; Messing and Brodeur 2018). If this approach yielded the only accurate measure of likely ecological risk associated with enemy release, few would quibble with the cost and delays. Here, we considered a few particularly wellstudied natural enemies in their non-native ranges, chosen to represent a range of feeding habits from relatively specialized to relatively generalized. Intriguingly, this selective review suggests no clear relationship between specialization and safety. Rather, existing work has found non-target effects across ranges of specialization, varying in the number and strength of feeding relationships, and of effects operating through direct and indirect channels, rather than any simple increase in risk as generality increased.

We contrasted the results from our selective review of the few most-detailed ecological case studies that were available, with a simple graphical model of the relationship between degree of specialism/generalism and impacts on target and non-target prey (Fig. 2). We emphasize that, even if the case studies perfectly fell along the line predicted by the null model, nine case studies would be far too few to confidently reject or accept the model's validity. We predicted that apparent competition might quickly amplify any non-target effects of relative specialists, as natural enemy densities bolstered by the control target allowed the agent to spill over to harm even relatively less-preferred native non-targets. Indeed, there may be some support for this possibility, as relatively specialized natural enemies that attack targets as different as exotic thistles and butterflies showed signs of apparent competition that substantially harmed natives. We predicted that these non-target harms would then grow more diverse, yet less impactful, with increasingly general feeding habits (Fig. 2). Here again, particular case studies provided evidence this might be the case, as several notorious lady beetle introductions appear, after careful consideration of recent findings, to be 
improving aphid biocontrol while displacing native lady beetles from managed habitats due to resource competition, rather than devouring them into extinction. However, it is important to note that a third case study, that of the tachinid fly $C$. concinnata, provided an example of substantial non-target harm from a moderate generalist. Finally, at the most extreme, while the broadest generalists by definition feed on many different non-target prey, these attacks are so diffuse that substantial harm is unlikely to be sufficiently widespread and consistent to lead to major declines in any particular prey species. Of course, alongside this, impacts on pests will likely be so diffuse as to make biological control introductions of the broadest generalists unlikely to measurably improve pest control.

An additional consideration that emerged from our selective review is that the strength of indirect effects that exert impacts on non-natives may be just as strong as those resulting from the direct effects that hostrange-testing seeks to minimize (Moore 1989; Pearson et al. 2000). This reflects a broader understanding in ecology that indirect effects are a key force that structures communities (Berlow 1999). We saw evidence for a relationship between degree of generalism, and the extent and strength of indirect effects impacting non-targets, similar to that seen for the direct nontarget effects discussed just above. When a natural enemy is highly specialized, and focuses its attacks on a single target prey/host, this can lead to sharp reductions in the target that have strong indirect effects on other native community members. This possibility has been most-discussed in the case of biocontrol of Tamarix, which serve as important nesting habitat for some rare riparian birds (Hultine et al. 2010; Sogge et al. 2008). But we would expect similarly-strong indirect effects anytime an invasive species is quickly and effectively pulled from the invasive range. Of course, the harm of these indirect effects will likely diminish through time, and native species move in to fill the niche(s) the now-controlled exotic once occupied. The broadest generalists might initiate a bewildering diversity of indirect effects, considering the large number of non-target prey they attack, but, because each direct link is relatively weak, we would not predict any single indirect effect to be as strong as those generally exerted by specialists.

Conservation biological control, which does not need to consider the non-target risks associated with classical biological control efforts, has often focused on bolstering generalist predator populations to strengthen natural pest control (e.g., Hessel 2013). This work provides a roadmap for the situations where addition of a generalist natural enemy might markedly strengthen pest suppression. First, generalists often form a "first line of defense" as pests colonize a field, because they are able to persist on non-target, alternative prey and are therefore present and active when initial pest colonization occurs and forming a "natural enemy ravine"(Symondson et al. 2000; Southwood and Comins 1976). However, this works best when generalists readily switch to attacking the control target when it becomes available (e.g., Settle et al. 1996). This important host switching behavior might be predicted with host-range testing before a release is made, such that this exercise might still be useful for generalists. We must also note that there could be cases where relatively rare (or slowly reproducing, etc.) native prey are the only option for a particular generalist species in some locations or times of year, such that non-target predation that makes up a relatively small portion of a generalist's overall diet could nonetheless yield substantial harm to the native prey. Indeed, this is precisely the reason that $C$. concinnata is so harmful to native moths in the eastern US. Second, while generalists may not exert a density-dependent increase in impact on a pest that is consistent with prey suppression, generalists can dampen the rate of pest increase and complement the density-dependent impacts of specialists (e.g., Snyder and Ives 2003). Third, generalists are particularly useful control agents in crops that face complexes of different pest species, because they can move from attacking one prey species to another as different pests become active or problematic throughout the season (e.g., Neuenschwander et al. 1975). Here again, how host switching impacts biocontrol will depend in part on relative preferences of a generalist for target versus non-target prey species. Finally, generalist predators that occupy different spatio-temporal feeding niches are most likely to complement one another, without co-occurring in space and time such that intraguild predation might be tempting (Snyder 2019). Together, these findings suggest when the addition of a new generalist to a guild of biocontrol agents might be particularly valuable to natural pest control. The case studies provided here suggest that a preference for human-modified over natural habitats, and an ability to 
aggregate at sites where target pests are reaching outbreak levels, are additional traits of some generalists that would be likely to strengthen their roles in classical biological control without enhancing risk to non-target natives.

\section{Future directions}

Altogether, our selective review suggests limitations in equating specialization with ecological safety. We propose that the current view relies too heavily on consideration of direct effects on non-targets. When instead setting these non-target effects within a realworld context where apparent competition and indirect effects are also considered, the relationship between degree of polyphagy and ecological safety becomes rather muddled. Looking from the community perspective, a "Goldilocks" situation might be best, with moderate generalists best able to persist among non-pest prey when needed, yet numerically respond to increases in pest densities when this is needed. That is, specialists might be a bit "too hot" and broad generalists "too cold", with intermediate generalists "just right". We also highlight the need to separately consider effects of introduced generalists in the unique context of agricultural fields versus in natural settings where non-targets might seek refuge.

We close by suggesting a few next steps that might be particularly fruitful areas for future exploration:

(1) Expanded meta-analysis of the specialism-risk relationship. Here, we focused on a few carefully chosen case studies where ecological studies were relatively abundant. Yet, this falls short of delineating the relationship between specialism and ecological risk across the full diversity of biological control agents that have been released worldwide. It is possible that a more comprehensive synthesis would find a general increase in substantial non-target harm with increasing generalism that our hand-picked small sample of case studies could not detect, and would be a worthy target of a true synthetic meta-analysis across all available case studies. In turn, a broader meta-analysis of this type would allow a formal test of the relationship between generalism and impacts proposed here (Fig. 2).
(2) How best to determine risk? While we suggest that specialized feeding, on its own, does not greatly predict degree of risk, we do not deny that host-specificity is and should remain an important part of risk assessments. However, the specificity of the proposed agent should be weighed against the expected pressure on the non-target groups effected. In addition, certain groups such as specialist herbivores and parasitoids may merit closer scrutiny than predatory agents since while the former groups are likely to have greater host-specificity, their life histories usually allow for rapid population growth and correspondingly large ecological effects. Likewise, indirect effects can form a key component of ecological risk and are worthy of greater attention.

(3) Increased post-release studies. While we do make the case that the damage caused by generalist biocontrol agents, and generalist predators in particular, are overstated, there is still a knowledge gap when it comes to nontarget effects of most introductions. In the future more focus should be placed on monitoring likely non-target hosts/prey. While this is likely to be difficult and potentially expensive, it would be crucial work in allowing adequate risk assessments in the future.

Acknowledgements This work was supported by Specialty Crop Research Initiative Grant No. 2015-51181-24292; Organic Research and Extension Initiative Grant No. 2015-5130024155; and Organic Transitions Grant No. 2019-03516; all from the USDA National Institute of Food and Agriculture.

\section{Compliance with ethical standards}

Conflict of interest The authors declare that they have no conflict of interest.

Open Access This article is licensed under a Creative Commons Attribution 4.0 International License, which permits use, sharing, adaptation, distribution and reproduction in any medium or format, as long as you give appropriate credit to the original author(s) and the source, provide a link to the Creative Commons licence, and indicate if changes were made. The images or other third party material in this article are included in the article's Creative Commons licence, unless indicated otherwise in a credit line to the material. If material is not included in the article's Creative Commons licence and your intended use is not permitted by statutory regulation or exceeds the permitted use, you will need to obtain permission directly 
from the copyright holder. To view a copy of this licence, visit http://creativecommons.org/licenses/by/4.0/.

\section{References}

Alyokhin A, Sewell G (2004) Changes in a lady beetle community following the establishment of three alien species. Biol Invasions 6:463-471

Andres LA, Goeden RD (1971) The biological control of weeds by introduced natural enemies. In: Huffaker CB (ed) Biological control: proceedings of an AAAS symposium on biological control, held at Boston, Massachusetts December 30-31, 1969. Springer US, Boston, MA, pp 143-164

Arnett AE, Louda SM (2002) Re-test of Rhinocyllus conicus host specificity, and the prediction of ecological risk in biological control. Biol Conserv 106:251-257

Babendreier D, Bigler F, Kuhlmann U (2006) Current status and constraints in the assessment of non-target effects. In: Bigler F, Babendreier D, Kuhlmann U (eds) Environmental impact of invertebrates for biological control of arthropods: methods and risk assessment. CABI Publishing, Wallingford, pp 1-14

Bahlai CA, Colunga-Garcia M, Gage SH, Landis DA (2015) The role of exotic ladybeetles in the decline of native ladybeetle populations: evidence from long-term monitoring. Biol Invasions 17:1005-1024

Baldwin PH, Schwartz CW, Schwartz ER (1952) Life history and economic status of the mongoose in Hawaii. J Mammal 33:335-356

Bannerman JA, McCornack BP, Ragsdale DW, Koper N, Costamagna AC (2018) Predators and alate immigration influence the season-long dynamics of soybean aphid (Hemiptera: Aphididae). Biol Control 117:87-98

Bean D, Dudley T (2018) A synoptic review of Tamarix biocontrol in North America: tracking success in the midst of controversy. BioControl 63:361-376

Benson J, Pasquale A, van Driesche R, Elkinton J (2003) Assessment of risk posed by introduced braconid wasps to Pieris virginiensis, a native woodland butterfly in New England. Biol Control 26:83-93

Benson J, van Driesche RG, Pasquale A, Elkinton J (2003) Introduced braconid parasitoids and range reduction of a native butterfly in New England. Biol Control 28:197-213

Berlow EL (1999) Strong effects of weak interactions in ecological communities. Nature 398:330-334

Bitume EV, Bean D, Stahlke AR, Hufbauer RA (2017) Hybridization affects life-history traits and host specificity in Diorhabda spp. Biol Control 111:45-52

Blitzer EJ, Dormann CF, Holzschuh A, Klein AM, Rand TA, Tscharntke T (2012) Spillover of functionally important organisms between managed and natural habitats. Agric Ecosyst Environ 146:34-43

Boettner GH, Elkinton JS, Boettner CJ (2000) Effects of a biological control introduction on three nontarget native species of saturniid moths. Conserv Biol 14(6):1798-1806

Brodeur J, Geervliet JBF, Vet LEM (1996) The role of host species, age and defensive behaviour on ovipositional decisions in a solitary specialist and gregarious generalist parasitoid (Cotesia species). Entomol Exp Appl 81:125-132

Brown PM, Roy HE (2018) Native ladybird decline caused by the invasive harlequin ladybird Harmonia axyridis: evidence from a long-term field study. Insect Conserv Divers 11:230-239

Brown PMJ, Ingels B, Wheatley A, Rhule EL, De Clerq P, van Leeuwen T, Thomas A (2015) Intraguild predation by Harmonia axyridis (Coleoptera: Coccinellidae) on native insects in Europe: molecular detection from field samples. Entomol Sci 18:130-133

Busch AK (2016) Life history of Pterostichus melanarius (Coleoptera: Carabidae) and its importance for biological control in field crops. Pennsylvania State University, Thesis

Callaway RM, DeLuca TH, Belliveau WM (1999) Biologicalcontrol herbivores may increase competitive ability of the noxious weed Centaurea maculosa. Ecology 80:1196-1201

Cameron PJ, Walker GP (2002) Field evaluation of Cotesia rubecula (Hymenoptera: Braconidae), an introduced parasitoid of Pieris rapae (Lepidoptera: Pieridae) in New Zealand. Environ Entomol 31:367-374

Ceryngier P, Nedvěd O, Grez AA, Riddick EW, Roy HE, San Martin G, Steenberg T, Veselý P, Zaviezo T, ZúñigaReinoso Á, Haelewaters D (2018) Predators and parasitoids of the harlequin ladybird, Harmonia axyridis, in its native range and invaded areas. Biol Invasions 20:1009-1031

Civeyrel L, Simberloff D (1996) A tale of two snails: is the cure worse than the disease? Biodivers Conserv 5:1231-1252

Clausen C (1978) Introduced parasites and predators of arthropod pests and weeds: a world review. Curculionidae. In: U Dep. Agric. Agric. Handb. https://geoscience.net/research/ 021/217/021217868.php. Accessed 13 Feb 2020

Cock MJW, Murphy ST, Kairo MTK, Thompson E, Murphy RJ, Francis AW (2016) Trends in the classical biological control of insect pests by insects: an update of the BIOCAT database. BioControl 61:349-363

De Clercq P, Mason PG, Babendreier D (2011) Benefits and risks of exotic biological control agents. BioControl 56:681-698

DeLoach CJ, Lewis PA, Herr JC, Carruthers RI, Tracy JL, Johnson J (2003) Host specificity of the leaf beetle, Diorhabda elongata deserticola (Coleoptera: Chrysomelidae) from Asia, a biological control agent for saltcedars (Tamarix: Tamaricaceae) in the Western United States. Biol Control 27:117-147

Diepenbrock LM, Finke DL (2013) Refuge for native lady beetles (Coccinellidae) in perennial grassland habitats. Insect Conserv Divers 6:671-679

Diepenbrock LM, Fothergill K, Tindall KV, Losey JE, Smyth RR, Finke DL (2016) The influence of exotic lady beetle (Coleoptera: Coccinellidae) establishment on the species composition of the native lady beetle community in Missouri. Environ Entomol 45:855-864

Dudley TL, Kazmer DJ (2005) Field assessment of the risk posed by Diorhabda elongata, a biocontrol agent for control of saltcedar (Tamarix spp.), to a nontarget plant, Frankenia salina. Biol Control 35:265-275 
Elkinton JS, Boettner GH (2012) Benefits and harm caused by the introduced generalist tachinid, Compsilura concinnata, in North America. BioControl 57:277-288

Evans EW (2004) Habitat displacement of North American ladybirds by an introduced species. Ecology 85:637-647

Follett PA, Johnson MT, Jones VP (2000) Parasitoid drift in Hawaiian pentatomoids. In: Follett PA, Duan JJ (eds) Nontarget effects of biological control. Springer, Boston, pp 77-93

Gassmann A, Louda SM (2001) Rhinocyllus conicus: initial evaluation and subsequent ecological impacts in North America. In: Wajnberg E, Scott JK, Quimby PC (eds) Evaluating indirect ecological effects of biological control. CABI, Wallingford, pp 147-183

Gerber E, Schaffner U (2016) Review of invertebrate biological control agents introduced into Europe. CABI, Wallingford

Greathead DJ, Greathead AH (1992) Biological control of insect pests by insect parasitoids and predators: the BIOCAT database. Biocontrol News Inf 13:61N-68N

Grez AA, Zaviezo T, Roy HE, Brown PMJ, Segura B (2017) In the shadow of the condor: invasive Harmonia axyridis found at very high altitude in the Chilean Andes. Insect Conserv Divers 10:483-487

Hagley EAC, Holliday NJ, Barber DR (1982) Laboratory studies of the food preferences of some orchard carabids (Coleoptera: Carabidae). Can Entomol 114:431-437

Hajek AE, Eilenberg J (2018) Natural enemies: an introduction to biological control. Cambridge University Press, Cambridge

Herr JC, Carruthers RI, Bean DW, DeLoach CJ, Kashefi J (2009) Host preference between saltcedar (Tamarix spp.) and native non-target Frankenia spp. within the Diorhabda elongata species complex (Coleoptera: Chrysomelidae). Biol Control 51:337-345

Hessel R (2013) Classical and conservation biological control of pest insects within prairie and crop systems. Grad Theses Diss. https://doi.org/10.31274/etd-180810-3452

Holt RD (1977) Predation, apparent competition, and the structure of prey communities. Theor Popul Biol 12:197-229

Honek A, Martinkova Z, Roy HE, Dixon AFG, Skuhrovec J, Pekár S, Brabec M (2019) Differences in the phenology of Harmonia axyridis (Coleoptera: Coccinellidae) and native coccinellids in Central Europe. Environ Entomol 48:80-87

Howarth FG (1983) Classical biocontrol: panacea or Pandora's box? Proc Hawaiian Entomol Soc 24:239-24

Hultine KR, Belnap J, van Riper IIIC, Ehleringer JR, Dennison PE, Lee ME, Nagler PL, Snyder KA, Uselman SM, West JB (2010) Tamarisk biocontrol in the western United States: ecological and societal implications. Front Ecol Environ 8:467-474

Hurd LE, Dehart PAP, Taylor JM, Campbell MC, Shearer MM (2015) The ontogenetically variable trophic niche of a praying mantid revealed by stable isotope analysis. Environ Entomol 44:239-245

Hurd LE, Eisenberg RM (1990) Arthropod community responses to manipulation of a bitrophic predator guild. Ecology 71:2107-2114

Kellogg SK, Fink LS, Brower LP (2003) Parasitism of native luna moths, Actias luna (L.)(Lepidoptera: Saturniidae) by the introduced Compsilura concinnata (Meigen)(Diptera:
Tachinidae) in central Virginia, and their hyperparasitism by trigonalid wasps (Hymenoptera: Trigonalidae). Environ Entomol 32(5):1019-1027

Kindlmann P, Ameixa OMCC, Dixon AFG (2011) Ecological effects of invasive alien species on native communities, with particular emphasis on the interactions between aphids and ladybirds. BioControl 56:469-476

Kok L (2001) Classical biological control of nodding and plumeless thistles. Biol Control 21:206-213

Kok LT, Surles W (1975) Successful biocontrol of musk thistle by an introduced weevil, Rhinocyllus conicus. Environ Entomol 4:1025-1027

Krombein KV, Hurd PD, Smith DR, Burks BD (1979) Catalog of Hymenoptera in America north of Mexico. Symphyta and Apocrita (Parasitica)

Lewis PA, DeLoach CJ, Herr JC, Dudley TL, Carruthers RI (2003) Assessment of risk to native Frankenia shrubs from an Asian leaf beetle, Diorhabda elongata deserticola (Coleoptera: Chrysomelidae), introduced for biological control of saltcedars (Tamarix spp.) in the western United States. Biol Control 27:148-166

Louda SM, Arnett A (1999) Predicting non-target ecological effects of biological control agents: evidence from Rhinocyllus conicus. In: Spencer NR (ed). Proceedings of the $\mathrm{X}$ international symposium on biological control of weeds. Montana State University, Bozeman, Montana, USA.

Louda SM, Arnett AE, Rand TA, Russell FL (2003) Invasiveness of some biological control insects and adequacy of their ecological risk assessment and regulation. Conserv Biol 17:73-82

Masetti A, Magagnoli S, Lami F, Lanzoni A, Burgio G (2018) Long term changes in the communities of native ladybirds in Northern Italy: impact of the invasive species Harmonia axyridis (Pallas). BioControl 63:665-675

McCann K, Hastings A, Huxel GR (1998) Weak trophic interactions and the balance of nature. Nature 395:794-798

Messing R, Brodeur J (2018) Current challenges to the implementation of classical biological control. BioControl 63:1-9

Messing RH (2009) Classical biological control in a new regulatory environment. In Proceedings of the 3rd international symposium on biological control of arthropods, Christchurch, New Zealand. 19-29

Messing RH, Wright MG (2006) Biological control of invasive species: solution or pollution? Front Ecol Environ 4:132-140

Moore NW (1989) The bird of time. Cambridge University Press, Cambridge

Moran MD, Hurd LE (1998) Trophic cascade from a generalist predator in a complex terrestrial community. Oecologia 113:126-132

Moran MD, Rooney TP, Hurd LE (1996) Top-down cascade from a bitrophic predator in an old-field community. Ecology 77(7):2219-2227

Neuenschwander P, Hagen KS, Smith RF (1975) Predation of aphids in California's alfalfa fields. Hilgardia 43:53-78

Niemelä J, Spence JR. (1991) Distribution and abundance of an exotic ground-beetle (Carabidae): a test of community impact. Oikos 351-359 
Niemelä J, Kotze DJ (2009) Carabid beetle assemblages along urban to rural gradients: a review. Landsc Urban Plan 92(2):65-71

Paxton EH, Theimer TC, Sogge MK (2011) Tamarisk biocontrol using tamarisk beetles: potential consequences for riparian birds in the Southwestern United States. Condor 113:255-265

Pearson DE, Callaway RM (2003) Indirect effects of hostspecific biological control agents. Trends Ecol Evol 18:456-461

Pearson DE, McKelvey KS, Ruggiero LF (2000) Non-target effects of an introduced biological control agent on deer mouse ecology. Oecologia 122:121-128

Polis GA, Myers CA, Holt RD (1989) The ecology and evolution of intraguild predation: potential competitors that eat each other. Annu Rev Ecol Syst 20:297-330

Prasad R, Snyder W (2006) Polyphagy complicates conservation biological control that targets generalist predators. J Appl Ecol 43:343-352

Pratt PD, Herr JC, Carruthers RI, Pitcairn MJ, Viellgas B, Kelley MB (2019) Release, establishment and realised geographic distribution of Diorhabda carinulata and D. elongata (Coleoptera: Chrysomelidae) in California, U.S.A. Biocontrol Sci Technol 29:686-705

Riddick EW (2017) Spotlight on the positive effects of the ladybird Harmonia axyridis on agriculture. BioControl 62:319-330

Schmitz OJ, Krivan V, Ovadia O (2004) Trophic cascades: the primacy of trait-mediated indirect interactions. Ecol Lett $7: 153-163$

Scudder SH (1889) The butterflies of the Eastern United States and Canada: With special reference to New England. Published by author, Cambridge, MA

Settle WH, Ariawan H, Astuti ET, Cahyana W, Hakim AL, Hindayana D, Lestari AS (1996) Managing tropical rice pests through conservation of generalist natural enemies and alternative prey. Ecology 77(7):1975-1988

Shine R (2010) The ecological impact of invasive cane toads (Bufo marinus) in Australia. Q Rev Biol 85:253-291

Sloggett JJ (2017) Harmonia axyridis (Coleoptera: Coccinellidae): Smelling the rat in native ladybird declines. Eur $\mathbf{J}$ Entomol 114:455-461

Snyder WE (2019) Give predators a complement: conserving natural enemy biodiversity that improves biocontrol. Biol Control 135:73-82

Snyder WE, Evans EW (2006) Ecological effects of invasive arthropod generalist predators. Annu Rev Ecol Evol Syst 37:95-122

Snyder WE, Ives AR (2003) Interactions between specialist and generalist natural enemies: parasitoids, predators, and pea aphid biocontrol. Ecology 84:91-107

Sogge MK, Sferra SJ, Paxton EH (2008) Tamarix as habitat for birds: implications for riparian restoration in the Southwestern United States. Restor Ecol 16:146-154

Southwood TRE, Comins HN (1976) A synoptic population model. J Anim Ecol 45(3):949-965

Stiling P, Simberloff D (2000) The frequency and strength of nontarget effects of invertebrate biological control agents of plant pests and weeds. In: Follett PA, Duan JJ (eds) Nontarget effects of biological control. Springer, Boston, pp 31-43
Symondson WOC, Glen DM, Erickson ML, Liddell JE, Langdon CJ (2000) Do earthworms help to sustain the slug predator Pterostichus melanarius (Coleoptera: Carabidae) within crops? Investigations using monoclonal antibodies. Mol Ecol 9:1279-1292

Thomas HQ, Zalom FG, Roush RT (2010) Laboratory and field evidence of post-release changes to the ecological host range of Diorhabda elongata: Has this improved biological control efficacy? Biol Control 53:353-359

Tomasetto F, Tylianakis JM, Reale M, Wratten S, Goldson SL (2017) Intensified agriculture favors evolved resistance to biological control. PNAS 114:3885-3890

Turner CE, Pemberton RW, Rosenthal SS (1987) Host utilization of native cirsium thistles (Asteraceae) by the introduced weevil Rhinocyllus conicus (Coleoptera: Curculionidae) in California. Environ Entomol 16:111-115

van Driesche R, Cock M, Winston R, Reardon R, Weeks RD Jr (2018) Catalog of species introduced into Canada, Mexico, the USA, or the USA overseas territories for classical biological control of arthropods, 1985-2018. USDA Forest Service, Forest Health Assessment and Applied Sciences Team, Morgantown, West Virginia. FHAAST-2018-09.

van Driesche RG, Nunn C, Kreke N, Goldstein B, Benson J (2003) Laboratory and field host preferences of introduced Cotesia spp. parasitoids (Hymenoptera: Braconidae) between native and invasive Pieris butterflies. Biol Control 28:214-221

van Driesche RG, Nunn C, Pasquale A (2004) Life history pattern, host plants, and habitat as determinants of population survival of Pieris napi oleracea interacting with an introduced braconid parasitoid. Biol Control 29:278-287

Viglášová S, Nedvěd O, Zach P, Kulfan J, Parák M, Honěk A, Martinková Z, Roy HE (2017) Species assemblages of ladybirds including the harlequin ladybird Harmonia axyridis: a comparison at large spatial scale in urban habitats. BioControl 62:409-421

Ware R, Yguel B, Majerus M (2009) Effects of competition, cannibalism and intra-guild predation on larval development of the European coccinellid Adalia bipunctata and the invasive species Harmonia axyridis. Ecol Entomol 34:12-19

Webber RT, Schaffner JV (1926) Host relations of Compsilura concinnata Meigen: An important tachinid parasite of the Gipsy Moth and the Brown-tail Moth (No. 1363). US Department of Agriculture

Weseloh RM (1982) Implications of tree microhabitat preferences of Compsilura concinnata (Diptera: Tachinidae) for its effectiveness as a gypsy moth parasitoid. Can Entomol 114(7):617-622

Wiggins GJ, Grant JF, Lambdin PL, Ranney JW, Wilkerson JB, Reed A, Follum RA (2010) Host utilization of field-caged native and introduced thistle species by Rhinocyllus conicus. Environ Entomol 39:1858-1865

Zwölfer H (1979) Strategies and counterstrategies in insect population systems competing for space and food in flower heads and plant galls. Fortschritt Zool 25:331-353

Zwölfer H, Harris P (1984) Biology and host specificity of Rhinocyllus conicus (Froel.) (Col., Curculionidae), a successful agent for biocontrol of the thistle, Carduus nutans L.1. Z Für Angew Entomol 97:36-62 
Joseph Michael Taylor is an entomology $\mathrm{PhD}$ student using stable isotope and molecular gut-content analyses to understand the roles and impacts of arthropod generalist predators.
William Emerson Snyder is professor of agroecology and systems biology at the University of Georgia, examining how farming systems impact interactions among birds, predatory arthropods, herbivores, plants and microbes. 